Portland State University

PDXScholar

1976

\title{
Mental illness among Chinese in the United States: myth or reality?
}

Alex C. N. Leung

Portland State University

Follow this and additional works at: https://pdxscholar.library.pdx.edu/open_access_etds

Part of the Biological Psychology Commons, and the Multicultural Psychology Commons Let us know how access to this document benefits you.

\section{Recommended Citation}

Leung, Alex C. N., "Mental illness among Chinese in the United States: myth or reality?" (1976).

Dissertations and Theses. Paper 2586.

https://doi.org/10.15760/etd.2585

This Thesis is brought to you for free and open access. It has been accepted for inclusion in Dissertations and Theses by an authorized administrator of PDXScholar. Please contact us if we can make this document more accessible: pdxscholar@pdx.edu. 
AN ABSTRACT OF THE THESIS OF Alex C. N. Leung for the Master of Science in Psychology presented June ?, 1976.

Title: Mental Illness Among Chinese in the United States: Myth or Reality?

APPROVED BY MEMBERS OF THE THESIS COMMITTER

Ronald Smith, Chairperson

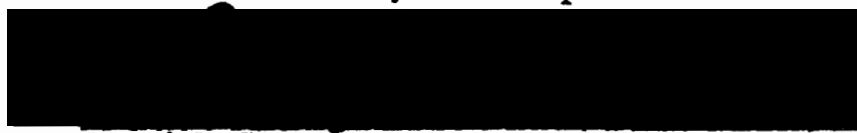

David Cressler

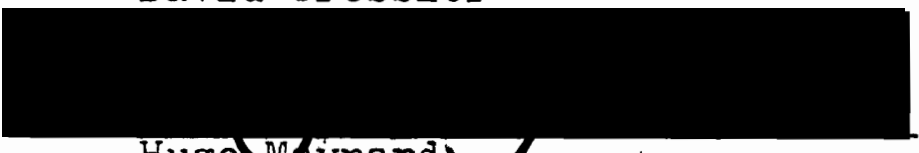

Hugo vaynard

Several mental health professionals have suggested that Chinese in the United States as a group are less subject to mental disorders than other races. Whereas other investigators have also indicated that due to the influences of cultural conflict and racism, Chinese in the United States are under greater emotional distress than members of the host society. When stress from these sources becomes too great, mental health problems are frequently the result.

The purpose of this library research thesis is to review the available research works related with Chinese. Americans' mental health problems in the hope of seeking answers to the following questions: 
1. Is mental illness among the Chinese a myth or reality?

2. If mental illness does exist among the group, what is the rate and how is it distributed in the Chinese population?

3. Are there some particular psychiatric maladies more commonly reported among the group than others?

First, the literature review confirms that mental illness does exist among the Chinese population residing in the United States.

second, the review shows that the rate of mental illness is not uniform within the group, in that among recent immigrants, the aged and students studying in the United States experience a higher risk of mental break-down than do female immigrants, the young or the native born.

Last but not least, research reveal that psychosomatization seems to be the origin of a significant portion of those reported cases of mental disorders.

These conclusions are not as extreme as those suggested by Tom in his Chinatown sample, namely that Chinese-Americans have an extremely high rate of mental illness:" However, they do indicate the mental health needs of Chinese are sufficent to warrant greater concern. Several suggestions on how to improve the mental health care for Chinese are made in the text. They include training bilingual professionals and paraprofessionals; modifications in therapeutic concepts and techniques; setting up community health programs in China- 
towns and encouraging more research to be done in this particular area. 
MENTAL ILLNESS AMONG CHINESE IN THE UNITED STATES: MYTH OR REALITY?

by

Alex C. N. Leung

A thesis submitted in partial fulfillment of the requirement for the degree of

MASTER OF SCIENCE

in

PSYCHOLOGY

Portland State University

1976 
TO THE OFFICE OF GRADUATE STUDIES:

The members of the Committee approve the thesis of Alex C.N. Leung presented June 7, 1976

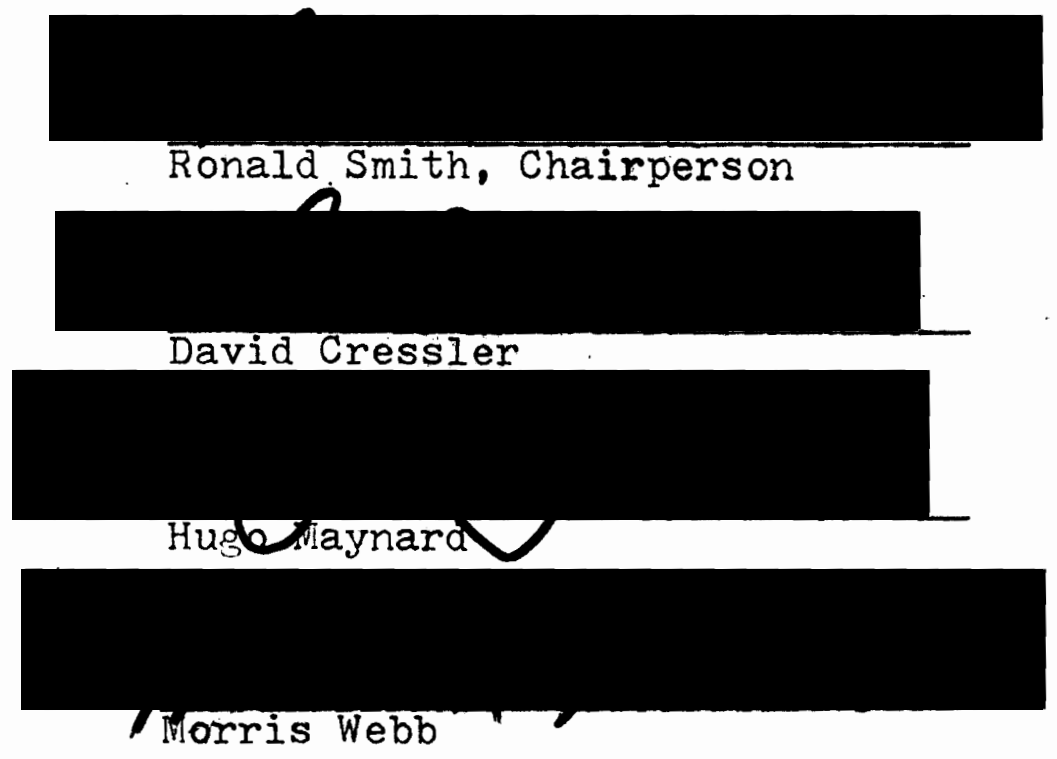

APPROVED:

Robert E. Jones, Jr, Had, Departuent of Psychology

Richlard B. Halley, Acting Dean/for Graduate Studies
and Research 


\section{ACKNOWLEDGEMENTS}

I thank the professors who gave their time to serve on my committee, Ronald Smith as chairperson, David Cressler, and Hugo Maynard. They have given me the freedom to pursue the topic of this thesis where the literature indicated without bias within the limitations of my own judgement. On the other hand their reading of the manuscript and commentary have been of valuable assistance. I especially thank them for the confidence they have shown in me. 
TABLE OF CONTENTS

PACE

ACKNOWLEDGEMENTS . . . . . . . . . . . . . . .

LIST OF TABLE

vi

CHAPTER

I INTRODUCTION . . . . . . . . . . . . I

II THE MYTHS OF CHINESE MENTAL HEALTH . • • • . 2

II THE MYTHICAL AND THE ACTUAL:

A CLOSER IOOK . . . . . . . . . .

IV MENTAL DISORDER AND CHINESE • . . . • . . 18

Incidence of Mental Disorder . . . . 18

Determinants of Mental Disorder. . . . 29

Migration Factors

Cultural Factors in Chinese Behavior

Contemporary Social Condition

Psychological Impact of

Studying Abroad

Somatization of Mental Disorder . . . 34

Alcoholism . . . . . . . . . 41

The Elderly and Mental Disorder. . . . 42

V TREATMENT CONCERNS AND RECOMMENDATIONS . . . 47

Modifications in Service Delivery . . 47

Bilingual Therapist

Bilingual Paraprofessionals

Changes in Therapeutic Concept

Techniques

Irregular Drop-in and Brief Treatment

Individual Treatment versus

Group Treatment

Medication 
CHAPTER

PAGE

A Community Mental Health Program for Chinatown . . . . . . . 52

Further Research . - . - . . . 55

A SEIECTED BIBIIOGRAPHY • . • • . . . . . . . . . . 57 
I Admission by Decade by Diagnosis: 
CHAPTER I

INTRODUCTION

For many mental health professionals in the United States, Chinese-Americans are an enigma in the mental health field. While there has been rising interest in the benefits of mental health services, Chinese-Americans have remained distant from and suspicious of such services. The clinic and hospitalization rate of psychiatric services for ChineseAmericans is very low. Such statistics are often inter-. preted as a sign that Chinese-Americans have few mental health problems or that there is a well-organized system of mutual help within the Chinese community. These interpretations are largely unsubstantiated and have been challenged by increasing numbers of Asian-American scholars and Community leaders who say that the traditional mental health institutions and services are not utilized because there is the barrier of language and culture which can be overcome only by providing bilingual, bicultural services located in the community.

The purpose of this review is to substantiate the latter reasoning by looking into more detailed research data and case studies and hopefully to come up with some remedial methods for the problems involved. 
CHAPTER II

THE MYTHS OF CHINESE MENTAL HEALTH

Chinese residing in the United States have always remained as a relatively faceless and nameless population. A lot of misinterpretations about their ways of life are caused by their anonymity in the American society. Even social scientists have only limited knowledge of the behavior patterns of the Chinese. Hence for those mental health professionals who are unfamiliar with the Chinese ethnic group, the following reasons probably cause them to think mental illness rarely occurs among the group.

First, relatively few such investigations have been undertaken of the Chinese in American society, and in the specific area of mental illness, only a few brief reports can be found in the literature. This general lack of research on psychopathology among the Chinese in American society may be in part due to the small number of social scientists who might exhibit an interest in them. The notion of being a research sample usually gives the impression of being "exploited" in the Chinese mind; hence their resistance to being studied (Sue and Sue, 1972). Other problems such as language, the availability of culturally fair research instruments also contribute to the paucity of research data. Second, since the Chinese arrived in America, they 
have been stereotyped as 'bestial celestials', 'atheistic heathens', 'opium smokers', 'gamblers', and 'gangsters'. Terms like 'yellow', 'slant eyed' and 'pigtailed' were being used to denote racial and cultural differences of the Chinese people in general.

After World War II, the negative attitudes towards the Chinese declined drastically, mainly due to the friendship established in fighting the war with Americans as allies. Chinese are now considered as a 'model minority'. They are described as patient, clean, hard-working, courteous, realistic, secure and unanxious. The prevalent belief is that the Chinese family system and their segregated positions in the larger society have successfully insulated them from the stresses and anxieties of modern life. Accordingly, many health professionals usually consider that Chinese often accept life as it is. Some even further assume that Chinese as a group are less subject to mental disorder than others, just from the above positive stereotypes alone (Barnett, 1955; Lin, 1953; and Kung, 1962). In a way, this shift from a negative to a positive kind of stereotyping has caused mental professionals to overgeneralize the Chinese as the 'well-adjusted people' and have little emotional problems. Third, the traditional Chinese concept of mental disorder often suppresses the reporting of its true incidence. Chinese families stress that its members must receive a good education, be obedient to parents, and give the family a good name. 'Bad' behavior on the part of a member, such as ex- 
hibiting psychopathology or antisocial behavior, brings shame on the entire family. Because of their strong sense of shame and pride, they have the tendency to hide their emotional problems for fear of social stigma if their friends learn of it. They prefer to solve the problems themselves and usually seek outside help only when their problems have reached the crisis stage.

In the early period of Chinese settlement in the United states, many potential patients of the asylum were protected from commitment by family members. Others may have been placed in a 'pest house', quartered by the Chinese Six Companies ${ }^{l}$ to send back to China (Jew and Brody, 1967). It is only in recent years, as the Chinese become more acculturated to Western ideas, that they have begun to accept the idea of placing the mentally ill in mental health agencies' care. Consequently, it is obvious that the utilization of mental health services is an inappropriate indicator of the adjustment of Chinese. In fact, some questionable research has indicated that the reverse is true. That is, while Chinese represent only a small proportion of mental institutions' admissions, they may exhibit greater severity in disorders. This would imply only the most disturbed Chinese seek treatments; those with milder disorders fail to use the service. Support for this notion - low utilization of

${ }^{I}$ Predecessor of the Chinese Consolidated Benevolent Association.: Its paramount function is to promote the welfare of every Chinese in the United States. 
facilities but greater severity among those being seen has come from a study of Chinese patients at a psychiatric facility, located in Los Angeles' Chinatown (Brown, Stein, Huang and Harris, 1973). However, due to the limited setting of the study, the generality of findings is questionable. Fourth, even if the Chinese are willing to seek help, they have always had difficulties in finding the appropriate facilities to handle their emotional problems. As we all know, psychotherapy is essentially a white-middle-class activity. It is intended for someone with high verbal functioning, a willingness to express emotions and a great tolerance for ambiguity. However, Chinese, as part of their ethnic characteristics, have learnt to inhibit their emotional expressions. They are reluctant to express their feelings and talk about their personal problems. They do not recognize a connection between previous events, and the emotions associated with those experiences, and their current circumstances and symptoms of emotional disorder. Symptoms are often attributed to present situations only. They expect concrete and substantial services that can been seen and tangible. Such a matter-of-fact and concrete approach is evidently cultural too. Few Chinese patients seek psychiatric help without asking for concrete assistance. Similarly, they do not feel they have been helped if the professionals gives them only emotional support and does not give them concrete services, such as financial assistance or help 
in finding jobs. What Eric J. Carlson summarizes as the difficulties in doing psychotherapies with minority clients applies to this particular situation very suitably. He says:

.... In this unique context, standard handbooks on counselling are, I submit, inadequate. It is apparent at once that most of these textbooks are written by academics and tailored to a white middle-class Euro-American audience. Our clientele is neither white, Euro-American nor middle-class. 2

Also, the kind of psychotherapy that is suitable for Chinese patients is limited to individual treatment category. The close-knit quality of the Chinese ways of living is an important reason to avoid group modalities of treatment. The Chinese are in the habit of keeping all of their difficulties within their immediate family. Discussion of emotional or interpersonal problems will be made almost impossible in a group of partial if not total strangers. The limited format of individual treatment decreases the already low rate of psychiatric treatment to an even lower level.

Then, there is the language barrier which often exists between the professional and the Chinese clients. Professional assistance itself may be unresponsive to the needs of those who do not understand the English language, which unfortunately includes at least one-third of the Chinese population in America. In the city of Los Angeles, which pro-

${ }^{2}$ Carlson, Eric J. Counselling in Native Context. Canada's Mental Health, V. 23. \#I, Mar. 75, p. 7-9 
bably holds the third largest number of Chinese in the nation, there is only one bilingual Chinese-American psychiatrist (Brown, et. al. 1973). Apparently for those Chinese-Americans who have been assimilated into the mainstream of Ameri-. can life and have entered the mental health field at the same time, they often do not share either the culture or the language with the rest of the Chinese immigrants.

Moreover, since more than one dialect is spoken by the Chinese, the therapist has to have a multi-dialect capability in order to have a meaningful communication between ciients and therapist.

The therapist's bicultural familiarity is equally important with his or her language abilities. Familiarity with the life style in China and Hong Kong permits the therapist to assist the patients to place their current circumstances into realistic perspective. This lack, in part, may very well be the cause of the unresponsiveness of professional help towards the Chinese' need for mental health service. It is only due to the recently increasing amount of data that researchers have begun to cast doubts on the popular belief that Chinese are well-adjusted, and the concept of them as the model minority figure (Jew and Brody, 1967; Tom, 1968; Berk and Hirata, 1973; Sue and McKinney, 1974; Brown, Stein, Huang and Harris, 1974). 
CHAPTER III

THE MYTHICAL AND THE ACTUAL: A CLOSER IOOK

In a Minnesota Multiphasic Personality Inventory (MMPI) study, comparisons, between Asian-American and non Asian- ' American students indicated that Chinese students (when compared with control students) possessed more pronounced MMPI scale elevations and exhibited problems involving somaticcomplaints, family discord, and social inversion. However, owing to the fact that the extent of culture bias in the MMPI performance of Chinese is unknown, the results of this particular investigation demand cautious interpretation.

In a current survey of New York's Chinatown, the author did point out the most serious health problem faced by the residents in Chinatown is that of mental health.

As there are few psychiatrists and even fewer bi-lingual Chinese psychiatrists, paraprofessional counselling services are desperately needed. Mental illness, suicide, asocial behavior and withdrawal from society are all commonly found in various ghetto environments. Many of the new immigrants face cultural: shock, and many of the sojourners, knowing they can never go back to China, fall into severe states of depression and psychosis. 3

${ }^{3}$ Chin, Ricky. New York Chinatown Today: Community in Crisis in Roots: An Asian American Reader. Amy Tachiki. and others (eds.). Ios Angeles, Continental Graphics, 1971, 282-294 
A lot more can be said about the cultural shock these immigrants receive as they come to settle in the United. States. Chen points out in his article on the Chinese community in Los Angeles that there is a growing rate of mental illness among the recent immigrants (Chen, 1970). This is not surprising if one looks at the process of immigration closely. It is essentially a process which leads to the disruption of familiar life styles. It involves total disintegration of the person's role relationship, loss of social identity, and major shifts in the value systems and behavior patterns.

Handicapped by the language problem, most of the immigrants are unable to find employments which are equivalent to their original levels of salary and status. Even such professionals as accountants, lawyers, doctors, teachers, who are proficient in their native language, must accept menial jobs that are below their dignity and respect. 4

It is an upheaval and disequalibrium of catastrophic proportion which can be considered as a major crisis. But most of the immigrants are not prepared for all these traumatic experiences at all. They have heard from friends and relatives all these positive, tempting things about America the land of opportunities, where everyone can have a share of the good life they see in the movies and televisions. As a

${ }^{4}$ Chen, Pei-Ngor. The Chinese Community. in Los Angeles. Social Casework, Dec., 1970, 591-593 
result, they have all these high hopes about coming to America. Once they have arrived, they quickly learn that the American streets are not paved with gold. The rainbow they had conjured up in their minds based on popular misconception of the United States vanished and their disillusionment is great. The following episode of Mr. King provides a striking case example.

Through the sponsorship of a brother who was an American citizen, Mr. King came to the United states from Hong Kong with his wife and four children, who ranged from two to ten years of age. Mr. King was a tailor by profession and had a history of tuberculosis, which was no longer active. His family had no knowledge of English and only a limited knowledge of Chinese. Informed by the brother that they would have no difficulty in settling in America, Mr. and Mrs. King sold all their possessions and spent most of their savings to purchase six airplane tickets. Upon arrival, Mr. King was immediately sent to a sanatorium for observation of his tubercular condition. His brother said he was unable to help him financially because he had six children of his own, and Mrs. King was unable to find a job because of the language barrier and the fact that she had to take care of her four children.

The family moved to a small, one-room apartment on the fringe of Chinatown. Pride and fear of deportation prevented them from asking for public financial assistance. The older two children were placed in a class for mentally retarded children until they were able to learn sufficient English to enter the appropriate grade levels. The scanty savings the family had brought from Hong Kong were soon completely spent despite their thrift. The family could no longer return to Hong Kong even if they wanted to do so. 5 
A cross-cultural study between Chinese and Eskimos contributed by three researchers explains the above misfortune very appropriately. Chance, Rin and Chu suggest that in rapidly changing societies, adequate knowledge of modern patterns of life together with a strong sense of one's own cultural identity provide people a psychic and cultural integration which promotes mental health. In contrast, individuals whose strong modern identification is not matched by sufficient knowledge of modern social life show a higher risk of psychic stress and corresponding symptom rate (Chance, Rin and Chu, 1967). This is exactly what happened in the case of Chinese immigrants.

When the immigrants bear children in America, a new source of mental maladjustment is being projected from the older generation to the younger. For those who are born in America, known as Jook-Sing ${ }^{6}$, are faced not only with tension common to all young Americans, but also with cultural value conflicts with their foreign-born parents. Such an emotional conflict, engendered by the impact of culture contrast, can be wery severe. The cause of the conflict is that 'cultural' superego and family mores assume heightened significance in the relationship of immigrant parents to their children. Most immigrant parents are likely to stress more rigidly their old World traditions in a new country than in their native land

${ }^{6}$ A Chinese term referring to chinese who lacks the knowledge of his own traditions and culture. 
to protect themselves in their strange and insecure environment. This, in turn, increases the defiance in the younger generation and makes them perceive their parents not only as the enemies, but also as the exponents of the old culture which sets them apart from those with whom they desperately seek to identify.

The immigrant parents, acting according to the old Culture, demand respect for unconditional parental authority and ever-lasting filial devotion from their children. The latter having learned about the American democratic values and ideals naturally find such demands hardly acceptable. The gap has widened to the point that despite the fact that the two generations may possess the same oriental faces, they actually share little common ground. In many cases, they do not speak the same kind of language. It is not surprising then that the parents who are the executors of the traditional way of life become the cathartic target of the youth's hatred. This discord again deepens the cultural conflict and invokes in the adherents of the Confucian doctrine an internalized conviction of sin and feeling of guilt which lead to intense inner suffering of the youth. The following is a description of what exactly happens in a Chinese students's fight again such a state of internal conflict.

Janet is a twenty-one year old senior, majoring in sociology. She was born and raised in Portland, Oregon, where she had 
Iimited contact with members of her own race. Her father, a second-generation Chinese-American, is a fifty-three year old doctor. Her mother, age forty-four is a housewife. Janet is the second oldest of the three children, has an older brother (currently in medical school) and a younger brother, age seventeen.

Janet came for therapy suffering from a severe depression reaction manifested by feelings of worthlessness, by suicidal ideations and by inability to concentrate. She was unable to recognize the cause of her depression throughout the initial interviews. However, much light was shed on the problem when the therapist noticed an inordinate amount of hostility directed towards him. When inquiries were made about the hostility, it became apparent that Janet greatiy resented being seen by a Chinese psychologist. Janet suspected that she.had been assigned a Chinese therapist because of her own race. When confronted with this fact. Janet openly expressed scorn for 'anything which reminds me of Chinese'. Apparently she felt very hostile towards Chinese customs and, especially, the Chinese male, whom she described as introverted, passive, and sexually unattractive.

Further exploration revealed a long-standing history of attempts to deny her Chinese ancestry by associating only with Caucasians. When in high school, Janet would frequently bring home white boyfriends, which greatly upset her parents. It was as though she blamed her parents for being born a Chinese, and she used this method to hurt them.

During her college career, Janet became involved in two love affairs with Caucasians, both ending unsatisfactorily and abruptly. The last breakup occured four months ago when the boy's parents threatened to cut off financial support for their son unless he ended the relationship. Apparently, objections arose because of Janet's race.

Although not completely conscious, Janet was having increasing difficulty with denial of her racial heritage. The break-up of her last torrid love affair made her realize that she was Chinese and not fully accepted by all segments of society. At first, she vehemently and bitterly denounced the chinese for her present dilemma. Later, much of her hostility was turned inward against herself. Feeling 
alienated from her own subculture and not fully accepted by American society, she experienced an identity crisis. This resulted in feelings of worthlessness and depression. It was at this point Janet came for therapy. ?

This agrees with what Abel and:Hsu indicate in their early study on Chinese personality (Abel and Hsu, 1949). They observe that in the American-born subjects, there is a breakdown of status personality role and a merging into the American way of life where less rigid control, more spontaneity, and more overt expression of feelings are. allowed.

As indicated in the case of Janet, racial discrimination constitutes another major factor on the Chinese. mental adjustment. The sad fact is discrimination has never been a new experience to the Chinese in the United States. There has been a definite tone of subtle coercion and often a policy of 'second class citizen' imposed on them throughout the history of their settlement in America. On February 16, 1854, the Alta California stated, "If the city continues to fill up with these people, it will ere long become necessary to make them the subjects of special legislation". Later, the antipathy increased to the point of using anti-Chinese agitation embodied in political actions like the Foreign Miner's Tax and Exclusion Acts. All this

${ }^{7}$ Sue, Stanley and Sue, W. Derald. Chinese American Personality and Mental Health. Amerasia Journal, 1971, . . 1, No. 2, 36-49 
legislation was actually implying official sanction of the prevalent hostility towards the Chinese. California's second constitution in 1879 also prohibited employment of Chinese in state, county and municipal government work. The violence directed at the Chinese surfaced on various occasions throughout the nineteenth century. In the Los Angeles. riot of 1871, a white mob killed at least nineteen Chinese; in the Rock Springs Massacre of 1885 in Wyoming, twentyeight Chinese were killed; at Truckee, California, in 1878, 1000 Chinese were driven out of town.

Such biased attitudes did not improve until the outbreak of the Second World War, at which time the United States was fighting the war with China as its ally. It was only then that the Federal Exclusion Act was repealed. Since then the social status of the Chinese-Americans have advanced a great deal. Now, there are Chinese engineers, physicians, dentists, lawyers; some are even city councilmen, senators, judges and not to mention, Nobel Prize winners.

But even now, today's Chinese-Americans are still suffering from various degrees of subtle forms of discrimination. There are still some business practices which keep Chinese from attaining high executive positions in large corporations. Sometimes, the kind of discrimination received by Chinese is far less subtle. What happened to Esther Lau was a tragic example (Wong. 1975). She was 
raped and physically abused by two California Highway Patrol Officers while she was being stopped for weaving on the freeway. After her traumatic experience, she was then charged with committing three offenses: the traffic violation for which she was originally stopped; resisting arrest, and battery against a police officer. Undoubtedly, these various forms of racism have left their marks on the personality of Chinese. The case of Chune confirms the above assumption.

.... Ever since Chune can remember, he had to work for 'white' people. He resented the fact that he always had to 'please' them. All his life he felt white people were 'superior' to Chinese. Inspite of many critical feelings towards Americans, he wished he could be an American. He felt deeply ashamed of being Chinese.

When the therapist reflected that it must have been confusing for him to have lived in two entirely different cultures, Chune felt grateful that the therapist could understand him, for he finds it difficult to make an adjustment to either one. He feels different among Americans, and equally different among Chinese. 'I feel I'm a stranger everywhere, $I^{\prime} m$ even a stranger to my mother. I feel I'm all alone in the world.'

As therapy progressed, he became increasingly outspoken in his dislikes for China. He exclaimed, 'I feel everything is wrong with China.' The more he verbalized feelings of shame, the more it became apparent that the shame was related to his own person. As he became aware of it, he related it primarily to his 'small size' and some of his other Oriental features. He felt he didn't look like a man. To him, all Americans appeared manly, husky, and superior. Also his poor English bothered him. He resented the fact that 'even though I was born here, people call me Chinese.' With a good deal of feeling. he often commented, 'I wish I were white.' Being white meant to him feeling secure, justified in being self-assertive; whereas 
being Chinese was identical with submission, discrimination and rejection. A strong positive transference relationship stimulated fantasies such as being adopted by a white parent or wanting to marry a white girl. 8

Such marked positive transference is evidently a way of 'identifying with the aggressor'. This stems primarily from the fact that the individual tries to conceal his deep feelings of hatred of a white authority figure because of his fear of retaliation. The idealization of, and identification with, a white parent figure is then often extended to the white race as a whole, thereby intensifying already existent racial and intra-psychic conflict and distortion of transference responses.

All in all, the above data did point out one thing, i.e. one can say with a lot of confidence that mental disorders among Chinese are by no means as rare as Westerners think, and that the Western explanatory concepts are also valid in the symptomatology of these disorders (Yap, 1967).

${ }^{8}$ Sommers, Vita $S$. 'Identity conflict and acculturation problems in Oriental-Americans. American J. of Orthopsychiatry, $1960,30,637-644$ 
CHAPTER IV

MENTAL DISORDER AND CHINESE

I. INCIDENCE OF MENTAI DISORDER

Having refuted the popular belief that mental disorders seldom exist among Chinese, the next question to ask will be: what kind of disorders are usually found among them?

Berk and Hirata did a study to examine trends among those Chinese who had been committed to mental hospitals in California over the past one hundred years, 1855-1955 (Berk and Hirata, 1973). The following trends are revealed by the data in Table 1 .

First, over $90 \%$ of all Chinese patients fell into only two diagnostic categories: affective reactions and schizophrenic reaction.

Second, $65 \%$ of Chinese mental patients committed during the 1850s were diagnosed under affective disorders. The percentage steadily declined over the century, less than seven percent were diagnosed in this category by the 1950s. On the other hand, there was a rapid increase in the diagnosis of schizophrenia, to the point where it encompassed fully $85 \%$ of those Chinese committed in the 1950s. Another interesting finding was an increase in diagnosis 'paranoia' immediately following the passage of Exclusion Act and outbreaks of violence directed against the Chinese. The rate jumped 
from three percent to nine percent during the period of exclusion and persecution, and then generally diminished to neglible proportions.

What these findings mean is uncertain. Whether they represent changes in the kinds of disturbances that Chinese experienced, reflecting the changing social conditions in which they were immersed, or whether they merely represent trends in psychiatric diagnosis and changing stereotypes of professional labelers is open to dispute. Also, increasing evidence suggests that the social characteristics of patients are an important determinant of the type of label an individual will receive.

In a more recent study comparing a sample of Chinese inpatients to a matched sample of Caucasian inpatients in a Los Angeles mental hospital for the purpose of characterizing and differentiating the types of severe mental health problems of the Chinese, different results are found (Brown, Stein, Huang and Harris, 1974).

In comparing, the diagnoses are broken down first into psychotic, neurotic, and personality disorders; and second, into schizophrenia, depression (including both neurotic and psychotic depression), and all others. No significant differences are found in the two breakdowns.

Once again, some possible biasing effects do remain in the study. There is the possibility that some of the more apparent 'psychotic' behavior is due to the misunderstanding of the Chinese patients because of the cultural differences 
and language barrier, since nearly half of the Chinese are found to have some difficulty speaking and understanding English.

Allowing for the above limitation, the data also illustrate two interesting facts: 1) the severe mental health problems among the Chinese tend to be those of immigrant status (i.e. not American born or Chinese students studying in the United States). 2) Chinese inpatients are more frequently men, experience a higher level of family discord, tend to have more difficulties with employment, and tend to be more frequently judged to be unimproved after treatment, compared to Caucasian inpatients.

The above findings can be partially explained. When a Chinese male immigrant becomes severely disturbed, he frequently is unable to work and therefore places a great deal of stress on the family. Under this pressure, the individual is brought by the family to the mental hospital. If the patient is a woman or a child on whom the family is not economically dependent, or a man who is not disturbed severely enough to encounter employment problems, it would be less likely that psychiatric hospitalization would be used. This hypothesis assumes that psychiatric hospitalization tends to be used by Chinese immigrant families only when they are driven by necessity such as the severe incapacitation of the head of the household.

Yamamoto (1968) indicated minority group members usually received less intensive psychotherapeutic help 
(meaning group or individual therapy session) than their Caucasian counterparts. This obviously affects their chances of improvement.

A point to bear in mind is that these studies involve mainly Chinese with immigrant status. The kind of mental disorders can be very much different if different kinds of Chinese population are used. This brings in the discussion of another study using Chinese students residing in the United States for its subjects. A significant difference is that after their mental breakdown, these subjects were treated back in their homeland, i.e. Taiwan, rather than in the United States.

Out of the forty cases reported, the researcher observed paranoid manifestations in the majority of them, 34 out of 40. cases (Yeh, 1972). A majority of the delusions and hallucinations manifested are predominantly persecutory in nature; they verbalize as being investigated, being watched, being followed, being poisoned, and their minds being read. Political coloration - such as being investigated by the F.B.I. or being suspected by Americans as Communists - is common. Suspicion of poison in drink or food as a method of persecution is also reported. This may be due to the traditional Chinese belief in persecution by slow-acting poison.

Sometimes the persecutors are fellow countrymen rather than the host ethnic group. Neurotic competition with fellow countrymen or frustrated dependency needs seem to create 
anxiety and a sense of failure in the students, which in turn leads to denial and the paranoid projection toward fellow countrymen. This can be illustrated by the following case:

Chinese student A, a major in Physics, suddenly developed the idea that a slowacting poison had been put into his soft drink after a ping-pong game with another Chinese student, $B$. He thought that the poison was put in by $\mathrm{C}$, to dull his mind, disturb his memory, and paralyse him. A's persecution complex was supposedly initiated by another Chinese student, $C$, who hated $A$. Student $C$ entered $A$ 's department two years ahead of him as a teaching assistant, and he had given $A$ a lower examination score than A thought was fair for a fellow countrymen. $A$, in turn, put some provocative notes on the blackboard in C's laboratory. Just before this episode, $C$ had failed a subject in the Ph.D. qualification examination given by A's professor. Therefore, A thought that C's action was a retaliation. 9

Among those factors that precipitate the Chinese students' breakdown, the following are the most often found: difficulties in academic achievement, finances, languages, interpersonal relationship, marriage and sex problems.

Most of the Chinese studying in the United States plan to stay a long time because of the long span of time their studies take. Finding an ideal partner for marriage is an important concern of these young people, especially the female students. With strong traditional prejudice against

9Yeh, Eng-Kung. 'Paranoid Manifestation among Chinese students studying abroad: some preliminary findings.' In Transcultural Research in Mental Health. Vol. II of Mental Health Research in Asia and the Pacific. William P. Lebra, (ed.) University of Hawaii Press, Honolulu, 1972, 328-329 
cross-cultural marriages, most of the Chinese students have to limit their choice to fellow countrymen or countrywomen only. Hence it is no easy task for them to choose their mates within the small social circle in which Chinese students tend to confine themselves.

For those who attempt to be iconoclasts, to date or marry outside their own ethnic group, their daring behavior usually creates considerable anxiety and a sense of shame. The student may be disparaged by fellow countrymen which may ultimately. Iead to severing their emotional ties with the other members of their families. A Chinese female student, following a courtship by an American whom she accepted, became ambivalent, depressed, and finally attempted suicide. Upon regaining consciousness from the head injury which she suffered in jumping from the second floor, she became acutely disturbed with delusions of being humiliated physically by Americans.

For the male student who had been preoccupied by sexual inadequacy at home, they sometimes develop the paranoia of being castrated by American girls. A 33 year-old married Taiwanese male, the father of two children and a passive. dependent, submissive type of a person, for a long time had suspected the infidelity of his active and domineering wife, whom he married through arrangements by his parents. He had however, never expressed his suspicion at home. His going to the United States at the age of 32 against his wife's wishes was excusable on the grounds that further overseas 
study would result in better job opportunities in the future. Perhaps he was only acting out his hostility toward his wife. In the United States, he became intimate with a female Chinese student, and when he received a letter from his wife accusing him of infidelity and desertion of the whole family, he became acutely disturbed and replied with a long letter full of anger and jealous delusions. Paranoid notions of being castrated followed this episode.

Another Chinese maie student, who had a strong affinity towards his mother, became annoyed by the feeling that his penis was small in comparison to those of his American classmates at the student dormitory. He later developed the idea of being looked down upon and eventually led to ideas of castration by American students. Consequently, he became very hostile and antagonistic toward them. Intensive study revealed, in these two cases and nearly all of the cases of similar nature, in 21 out of the 34 paranoid cases, emotional deprivation and disturbed family relations were found. In nearly all cases where there was an early death of a parent, the father was the one who had died, and the mother became a neurotic, overprotective, controlling figure with high expectations for the children's achievements.

The outcome of the treatments of those cases were generally encouraging. Only four cases out of the total forty remained unchanged. Their poor prognosis was significantly related to marked premorbid perșonality disorders and disturbed psychological relations in the family. In those 
cases with a favorable outcome after treatment, the return to the home country itseif seemed to release psychological tension considerably, and in some cases, it served to provide an opportunity for reality-testing.

It is the researcher's belief that psychotic students who break down abroad, especially paranoid cases, can be treated with much better prognosis in the home country than in the foreign country. Persecutory delusions about the school, immigration authorities, or the hospitalization mistreatments disappeared quickly after patients returned to Taiwan. An interesting fact is that sometimes the contents of a delusion or hallucination change, instead of disappearing after a return home by the patient. A male case had visual hallucinations of being Buddha, instead of Jesus Christ as he had had in the United States, as soon as he arrived in Japan enroute to Taiwan. These changes may be understood in light of the psychodynamics in the development of delusions or hallucinations and the changes brought about by returning home.

Once having returned home for treatment, most patients were able to cope with their emotional difficulties through the therapists' support, and their depressive symptoms usually diminished. However, when they were subjected to problems of similar nature to the one which had provoked their initial psychological difficulties, occasionally recrudescences were reported. The following case reported by Yeh is a good example of such a happening (Yeh, 1972). 
A Chinese male who was sent home for treatment from the United States because of a series of delusions and hallucinations of a predominantly persecutory nature committed suicide by taking a large dose of barbituates soon after his discharge from the hospital where he hal shown marked improvement after two months of hospitalization. It was found that the depression was precipitated by his receiving a letter from his American girlfriend who wished to visit him in Taiwan and who suggested the possibility of marrying him. They had once considered marriage while he was studying in the United States. He thought he did not deserve to marry her. Furthermore, marriage and subsequent departure to the United states would entail his leaving aging mother alone in Taiwan which he felt he should not do. Also, his future in the United States would have been quite uncertain.

During the long course of psychotherapy afterwards, he became depressed from time to time when he took on a new job or when he was assigned to a new project which required independent responsibility. He was overwhelmed by feelings of insecurity and strong ambivalent feelings of hostility and guilt towards his mother (the only member of the family who lived with him and for whom he felt responsible) were expressed during psychotherapy. The father had died in his early childhood, and as the youngest of his siblings, he had been brought up by his illiterate, old-fashioned mother with the financial assistance of the two older brothers who lived in Japan and Malaysia. He was the only one in the family who received a college education, and the older brothers had high expectations for his studies in the United States. While a student in Taiwan, he had never had time to examine himself, his ability to study abroad, his professional career, and his future life in general. It was during graduate study in the United States that he underwent the emotional turmoil of identity crisis which resulted in a loss of confidence and in his feeling of getting lost. 10

Though Yeh's study involved solely Taiwanese students, 
it can be inferred from his data that Chinese students coming from Hong Kong or other parts of Asia will undoubtedly be exposed to similar psychological tension. For some students, a desire to go abroad to study can be motivated by neurotic competition with others or by their parents who attempt to satisfy their own neurotic needs vicariously. To these people, having the chance to go abroad to study means bringing honor to the whole family. Failing to do so means losing. 'face'. Or occasionally, students just want to run away from the difficult situations at home, or they are making a blind effort to redeem failure at home by seeking better opportunities abroad. In any case, these students go abroad without insight into their own problems and without adequate preparation for the difficulties of study abroad. Ihis is certainly a serious problem from both the mental health and educational point of view.

If psychological interviews including careful inquiry into their health history, ability to adjust, and their life experiences are required of the students before their departure, it will not only serve to detect some easily overlooked psychiatric conditions but will also help to predict the possibility of future maladjustment or mental disorder. 
II. DETERMINANTS OF MENTAL DISORDER

A question may arise as to whether paranoid manifestations are more commonly found in the Chinese students studying abroad or similar data are also reported in other foreign students. Unfortunately, no studies are available to answer this question yet. Depressive symptoms and suicidal attempts have been reported among Japanese students studying in the United states. When these cases, were carefully read, it was noted that paranoid features were so apparent that paranoid psychosis could be the diagnosis (Shimazaki and Takahashi, 1967). However, intensive epidemiological study of the mental disorders in communities and the hospital statistics in Taiwan seem to indicate that paranoid symptoms are not more prevalent than other mental disorders among the Chinese in general. Since students studying abroad from these two ethnic groups share the high rate of paranoid manifestations, the following factors may be relevant to the explanation of their malady.

\section{Migration Factors}

Among those psychiatric disorders which have been found to be prevalent among migrating or displaced populations, paranoid manifestations have been reported to be common symptoms (Pedersen, 1949, Tyhurst, 1951). Chinese students have to undergo cultural shifts and environmental changes similar to those the immigrants have to experience when they come to the United States. The stress exerted by these changes 
results in psychological isolation, increased uncertainty towards self and relations with others, and communication problems. All these psychological problems eventually lead to projection and denial in the migrants and may probably cause their paranoid formations.

The native country of the migrant and the country to which he migrates can be very important to his ability to adjust in the new country. It can be assumed that the migration to a country with a basically similar culture, say from Canada to the United States, is easier than the move into a greatly different culture, from Asia to the United States, for example. The greater the cultural difference, the greater are the difficulties in adaptation and psychological adjustment. By the same token, the relative degree of technological development also affects the prospect of adjustment. It can be assumed that paranoid disorders are relatively common among the foreign students from non-Western, technologically less developed countries who migrate to study in developed Western countries. Reports of strong paranoid elements among psychotic foreign students from non-Western, less developed countries seem to support this assumption (Zunin and Rubin, 1967). To further substantiate the theory, studies of the mental health problems of the Western developed country migrants are necessary.

\section{Cultural Factors in Chinese Behavior}

Besides the migration factor cited above; characteris- 
tics of the Chinese culture appear to be relevant in the explanation of paranoid symptoms in Chinese students studying abroad.

Traditionally filial piety and respect for elders are the central code of discipline in the family. At the same time, the psychological foundation of Chinese society focuses on mutual interdependence among the members of the family. These characteristics result in the following behavior patterns which may lead to the developing of paranoid symptoms in Chinese students.

1) Chinese tend to feel insecure outside of the family or primary kinship group, this is especially true when they are residing in foreign countries. This is demonstrated by the strong cohesiveness among the Chinese students in the United States. Lack of emotional communication and intimacy with American and other foreign students, psychological isolation from them, and a strong tendency to maintain their own subculture are characteristics of the Chinese students at an American university (Leung, 1974).

2) The world outside of the family is generally regarded as potentially undependable and even dangerous.

3) Emphasis on keeping harmonious interpersonal relations makes the individual always conscious of others and sensitive to them. Much restraint on thoughts or behavior is emphasized so as to discourage any "faux pas" in front of others. These sources of regulating behavior in the host society appear to be either the real or fantasized presence of others who have the power to shame the students. 
4) Face-value is the dominant psychological mechanism in controlling one's behavior in Chinese culture (Hsu, 1954). In a shame culture, one may tend to project his faults to others when the experienced shame is too great and face is lost. The Chinese 'too much shame will turn into fury' is frequently used to explain violent or homicidal acts. This seems to be a very relevant expression for such a psychological mechanism.

Contemporary Social Condition

Taiwan, because of the political situation, is under strict security control. One must be extremely cautious about behavior so as not to get into any trouble with the government. This attitude may account for the prevailing defensive and distrustful behavior among the Taiwanese. Stated in the extreme, one will assume Taiwanese students will have higher rates of paranoid manifestation than Chinese students migrating from elsewhere. Eut once again, further studies comparing Chinese students from Taiwan, Hong Kong and other Asian countries are needed before we can determine the validity of the assumption.

Psychological Impact of Studying Abroad

To study abroad for advanced academic degrees in the western developed countries has always been the highest aspiration of young Chinese intellectuals. Successful study abroad means not only gaining in knowledge, but also good opportunities for financial security and better social standing. 
In a society where filial piety and conformity to elders demands are emphasized, the parents' desires usually play a major part in the students' decision-making. There is, consequently, a possibility that the motivation for their desired going abroad to study is a neurotic compensation of the parents and that the students' psychological readiness has never been taken into account.

The psychological pressure on these students is great. Failure in study not only means losing face for the students but for the parents and the family name as well. That is why even during times of emotional or mental stress in their studies, the Chinese students still feel compelled to write to their parents, to tell them how well they are doing in the foreign land. Many a time, they will even exaggerate their academic achievements and enjoyment of life a bit in order to reassure their parents who expect so much out of them. This fear of failure in their academic affairs and in losing face is so intense that it can very likely lead to mental breakdown.

With the above studies cited, it should be safe to infer that the kinds of psychological disorders Chinese suffer tend to be different from one group to the other. This is actually no surprise to people who are familiar with the Chinese population in the United States, because the immigrants and students have to go through some similar adjustment phases. The nature of the stresses upon them though may be very different. 
III. SOMATIZATION OF MENTAL DISORDER

In reviewing the data, the author did notice one common mental disorder among the Chinese. A significant portion of the literature being reviewed hinted that many of the reported psychological maladies could be psychosomatic in origin (Collier, 1974; Mansella, Kinzie and Gordon, 1971; Sue and Kirk, 1975; Sue and Sue, 1974; Tseng, 1973; Tseng and Hsu, 1969 and woods, 1928). The subjects involved in these studies were fairly heterogeneous and, as a result, the conclusion can pretty much apply to the Chinese population in general.

To test the hypothesis that Chinese and Japanese students exhibit more somatic complaints, Sue and Sue conducted an investigation to compare the MMPI profiles of AsianAmerican and non-Asian students utilizing a student health psychiatric clinic (Sue and Sue, 1974). Results indicated that Chinese students when compared with control students did show more somatic complaints. The researchers at first suspected that the Chinese's higher scores on scales indicating somatic complaints could be due merely to a greater severity of psychopathology rather than their higher tendency to somatize. In an attempt to control the severity factor, each Asian student was matched with a same sex control student in term of the score derived from Goldberg's formula (1965). The first control student having an equal or the closest score with that of an Asian student was se- 
lected. Using this procedure, Asians did not significantly differ from matched-control non-Asian in severity of disorders; but a significantly greater mean number of somatic complaints was still. observed in the Asian students. But because the cultural bias in the MMPI performance of Chinese and Japanese students is unknown, the results of this particular investigation still merit cautious interpretation.

In studies using Chinese subjects elsewhere, $R$ in and Yap reported at least two culture-bound maladies which fit into this psychosomatic category perfectly, namely Koro, and Frigophobia (Rin, 1965; Yap, 1951). These two psychiatric maladies have usually been found among the uneducated Chinese in the lower social levels.

The term "koro" refers to a state of the acute anxiety with partial depersonalization leading to the conviction of penile shrinkage and to fears of self-dissolution. Among the South Chinese (Cantonese), koro is known as Su-Yang. It has not been recorded among other peoples. The patient, usually a neurotic with sexual conflicts, e.g. conflict regarding impotence or masturbation, suddenly becomes seized with the conviction that his penis is shrinking into his abdomen. According to popular belief, if' this is allowed to happen, death ensues; hence the patient falls into a state of panic. $\mathrm{He}$ hastily resorts to various folk-lore remedies. First he tries to clamp his penis in a wooden-case used for holding a jeweller's balance; or failing this, ties a red strip around the penis, red being the color successful in warding 
off evil. Sometimes, instead of the above measures, the wife immediately practises fellatio to prevent further shrinkage. Inevitably, a great commotion is caused by his panic state and the patient has to be carried in distress to the hospital. That this is psychosomatic illness resting on superstition, there can be no doubt. There is a wealth of folk-lore in connection with this disease, but it is probable that actual hysterical anaesthesia of the penis or some disturbance of the 'body image' occurs.

Frigophobia or pa-leng in Chinese, means a morbid fear of cold. An abbreviated case history of a Chinese patient suffering from Frigophobia in Taiwan may be given by way of illustration.

S. was a patient who manifested 'frigophobia' symptoms whenever he suffered loss. He was born the eldest and only son of a rich traditional extended family. He slept with his grandmother up to the age of eleven and was babied by her. Like every Chinese mother and grandmother, she was concerned with his bodily health and especially with his warmth. She kept him overdressed and wearing a belly-band even into adult life. He was not permitted to leave the bed at night. Arrangements were made for him to urinate in bed until: he was eleven years of age. This was a precaution against catching cold.

When grown up, he became a general like his father. His wife was a woman older than himself, whereas it is usual for a Chinese man to marry a woman younger than himself. Because of wealth and social status, he was able to have several concubines. At the time of the Communist takeover in mainland China, he fled to Taiwan, bringing with him only money and one of his concubines.

Several years later, he learnt of.his father's death and his mother's sickness in mainland China. 
This precipitated his first attack of frigophobia. He presented himself at the hospital in the heat of summer swathed in many layers of clothing and quilts and complaining of feeling cold. He did not complain of feelings of depression and loneliness. This kind of attack recurred twice more, each time following a loss. In one instance it was loss of money, in the other, the loss of his concubine. Shock treatment and medication were ineffective. However, prolonged sleep therapy relieved him of symptom each time. In the hospital, a patient receiving prolonged sleep therapy is constantly attended by one female attendant, an "Amah", who stays in his room twenty-four hours a day, feeds him, baths him, and takes care of all his bodily needs. It seems evident that for this patient to have the exclusive attention of one older female who babied him during the course of prolonged sleep therapy produced the condition for his recovery. This suggests that his frigophobic symptom was regression in reaction to loss which served to recreate his situation as a child with his grandmother. 11

In reviewing the available cases on these two psychosomatic disordeas, the following similarities are discovered. Similarities between Koro and Frigophobia are: 1) a core symptom of extreme fear of loss of bodily energy or vitality; 2) imagined loss or deficiency in vital strength attributed to disharmony between Yin and Yang elements two complementary forces which according to Chinese belief have to be in harmony to ensure health; 3) association of the core symptom with various other psychiatric symptom; 4) self-administration of various remedies intended to counteract loss of vitality.

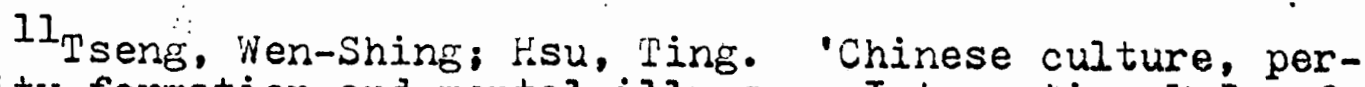

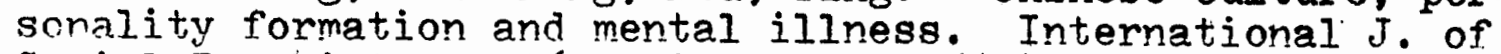
Social Psychiatry, 1969, Winter, V. 16(1), 5-14 
There are also basic dissimilarities: 1) Yang elements (semen and blood) are involved in Koro and Yin element (cold and wind) in Frigophobia; 2) the main feature of Koro is castration anxiety and that of Frigophobia fear of death through respiratory disease; 3) counterphobic measures adopted in Koro are display of sexual prowess and in Frigophobia wrapping up in protective clothing; 4) the personalities of Koro patients are characterized by overt aggressiveness, those of Frigophobia patients by inhibited aggressiveness; 5) Koro patients are athletic, Frigophobia pa-. tients asthenic or pyknic; 6) Koro patients tend to show deviant social behavior, such as drinking, gambling, and indiscriminate promiscuity; Frigophobia patients are apt to withdraw socially; 7) lack of maternal care in childhood is frequently reported by Koro patients, and maternal overprotection by Frigophobia patients.

Though no official reporting of Koro or Frigophobia cases have ever been recorded among the Chinese population in the United States, this does not necessarily mean the Chinese-Americans are immune to these two particular psychosomatic maladies. As Kitano pointed out, due to the very inefficient mental health service offered to the Asian-Ameri$\therefore$ cans, the actual rates and kinds of mental illness reported are often underestimated by the so-called 'funnel effect' (1969). However, other cases of mental illness in which the cause is being diagnosed as psychosomatic are not that infrequent among the Chinese-Americans. 
For example, a sister-in-law was cruelly overworked and imposed on. She came to the hospital to ask relief from gastric problems. On her way out, she suddenly fell on the floor palsied in all limbs. Likewise, a strong young automobile mechanic was harried by his mother and forced by her for private reasons of hers to move his own family and to live with his older brother's family. He grew depressed, lost weight, developed dyspepsia, could not sleep, and finally became so weak that he could not work.

Psychosomatic disorders are not only found in Chinese adults. Collier (1974) reported a Chinese twelve year old boy with a psychogenic vomiting problem.

Lee, a 12-year-old Chinese boy, small for his age, and the eldest of four children, was referred for psychological evaluation by his general physician. Lee had been nauseated and vomited frequently for some time. He often times described the feeling of impending vomiting as well. His parents became primarily concerned because of Lee's excessive preoccupation (nearing an obsession) with candy as a means of staving off or impending the feeling of nausea toward vomiting. Interestingly enough, he used primarily Iifesavers.

Both of Lee's parents were very quiet-spoken individuals, who seemed to pay high rewards to family members who were quiet and cooperative and exhibited don't-rock-the-boat types of behavior.

In discussing the problem with Lee, it soon became apparent that his vomiting, aborted vomiting and nausea were directly related to the amount of anxiety and stress he experienced. This became concretely clear after having Lee utilize a schedule to tally with slash marks the number of Lifesavers he utilized during the morning, afternoon and evening periods of each day of the week. It was of interest to note that the first week was near the beginning of school and he used a total of 119 Lifesavers. 
A significantly larger number of Iifesavers were consumed on Monday, there was a gradual decline and a rise again on Friday. He, himself noted that he bagan increased anxiety on Sunday evening, which reached a peak on Monday morning when anticipating school. This gradually decreased to Friday when he again anticipated Chinese classes after school. 12

Psychoanalyst Alexander asserted that whatever avenues of impulse expression are blocked, organismic responses are inevitable and the pattern is determined by the individual's psychological history. Following the same line of thinking, the present author hypothesizes that the commonly occuring psychosomatic complaints among Chinese may be due to their reluctance to admit psychological problems, since there is much shame associated with them. Physical conditions are better recognized and more acceptable.

To substantiate the logic involved in the hypothesis. the present author points out the special concern most Chinese have with their own bodies as reflected in their everyday colloquial, emotionally-laden language: statements such as lungs, hearts, heads, sex-organs, limbs and some are often mentioned in their daily conversations for special emphasis. There is one particular one which goes like this, 'It is so cold that I almost su-yang.' The speaker implies the extreme cold has almost caused his penis to shrink into his

12 Collier, Herbert I. The patient with somatic symptoms. In Problems in Psychotherapy: An eclectic approach. Klopfer, Walter G. and Reed, Max R. (eds.) Washington D.C., Hemisphere Publishing Corporation, 1974 
abdomen. This is an excellent example of how the Chinese are concerned with their body functions and their proneness to use it to somatize.

\section{ALCOHOLISM}

There is one particular mental disorder that is seldom reported among the Chinese Americans or the Chinese in other parts of the world. The problem is Alcoholism. Many mental health professionals believe that excessive use of alcohol is a symptom of personality problems and is the patient's way of coping with his life stresses. However, in this case, the author thinks the rate of alcoholism is significantly related to cultural differences.

The use of alcohol in China is as old as her history; alcohol is readily available and there is no moral prohibition against drinking. Alcoholism has never constituted a serious problem in Chinese society. Chinese drink mostly with meals and on ceremonial occasions. It is supposed to promote communication between people and one is encouraged to drink at a party so that acute intoxication sometimes occurs. But drunkenness in any other occasion is strongly disapproved. Drinking aside from at parties and occasionally with a meal at home is considered to be a sign of weakness and deterioration and is strongly frowned on by the family and society. As a result, chronic alcoholism is very rare. For the Chinese-Americans, the process of accultura- 
tion may have shifted their drinking habits a bit towards the western tradition. Such a shift can be evidenced by the bars in the Chinatown area and the cocktail lounges in many of the Chinese restaurants. It is not sure how much the shift has affected the rate of alcoholism among the ChineseAmericans. No official record of Chinese alcoholics was ever recorded in the literature reviewed. Since the recording of any mental disorder among the Chinese-Americans has always been unreliable, this consequently cannot be taken as no change in their rate of alcoholism. Research must be designed to explore this long-neglected area before any conclusive statements can be made.

\section{THE EIDERLY AND NENTAL DISORDER}

Among those Chinese who are in dire need of mental health care, several researchers have pointed out the group most in need of the service is the elderly (chen, 1970; Chin, 1971; Kalish and Yuen, 1972; Sing, Chan and Wang, 1973). According to the United States Immigration and Naturalization Service source, there were around 15,000 Chinese-Americans over 65 years old in 1970. San Francisco alone had an elderly Chiriese-American population of approximately 10,000 (SFCC, 1969), some two-thirds of the nation!s total, and Chinese communities of significant size also exist in Boston, Chicago, Honolulu, Los Angeles, New York, Oakiand, Philadelphia, Portland, San Antonio and Seattle. It is very likely that 
many elderly Chinese are not counted by the Census. For example, the official records show 47,000 Chinese in San Francisco in 1969 (SFCC, 1969), but unofficial estimates of well-informed observers run as high as 80,000 . Chances are there are many poor elderly Chinese who have been neglected. These elderly are apt to be underrepresented in the Census and in both the state and local surveys because they are among the most mistrustful of government agencies, suffer the greatest language handicaps, and often are poorly informed regarding worldly matters.

Most of these elderly Chinese are the 'sojourners' the old immigrants, mostly males, who came here as pioneers and left their families in mainland China. Lacking the skills of great value to an industrial society, many of them worked hard as laborers in the mines and on the railroads in the earlier part of this century. As a result, their history in this country has been, generally, one of struggle. They planned on returning to china after they made their fortunes but were unable to because of the change of government in China. They have lost contact with their primary family members permanently. Most of them have very little education in this country. As a result of all this, they feel stranded in a culture they do not understand and that they felt unable to influence.

China has always been described as a 'gerontocracy' because of the position of the elderly in the family and 
the general veneration of the aged in the Chinese world view. Ideally, old age is a time when one presides, both literally and symbolically, over a large group of co-resident kin. Unfortunately, the process of acculturation has taken much of these traditional values of Chinese 'filial piety' from the Chinese residing in the United States. For those who are fortunate enough to have their families with them, both the old and the young Chinese feel more comfortable when they live in separate households, The elderly person often prefers to live in Chinatown because he feels more at home there than in his children's attractive suburban communities where he cannot communicate with the neighbors.

Having lived in Chinatown all their lives, the elderly Chinese have not learned the English language. In addition to loneliness, ill-health, and the deep sense of hopelessness common to most old people, their problems are intensified by the language barrier. A great number live in poverty and fail to request financial assistance from either public or private social agencies because of their sense of shame and because of the language barrier. It is surprising to find many of these 'sojourners' living solely off their. own saving because they refuse welfare, suffer from poor health, malnutrition and mental illness which in many cases lead to suicide. The latter is indicated by the considerably higher than average suicide rate among the elderly in both San. Francisco and Los Angeles Chinatown areas (Tom, 1968 and Chen, 
1970). The following case of $\mathrm{Mr}$. W is a good illustration of what some of the Chinese elderly are experiencing.

Mr. W, 72 years old, lived alone in a dark, filthy, overcrowded hotel in Chinatown. He occupied a room for which he paid a monthly rent of thirty dollars, and he shared a common bathroom and kitchen with forty other tenants on the same floor.

Mr. W had come to the United States when he was in his twenties to work as a cheap laborer for the Pacific Railroad Company, leaving his village, wife, and one son behind in mainland China. When the Pacific Railroad was completed, he was laid off. Mr. W then worked as a cook in various chinese restaurants until he was sixty-nine years old. Because of the political changes in China, he had lost all communication with his wife and son. He had no relatives either in America or Hong Kong. While he had been working on the railroad, tiny bits of rock hit his eyes, and, as a result, he suffered from deteriorating eyesight.

Mr. W seldom went out of his hotel room. He ordered his meals from a nearby restaurant. He had few friends in Chinatown and they were too busy to visit him. Mr. W was poor, lonely, and depressed. 13

Also, prior to 1960, the elderly Chinese Americans had an unusualiy high rate of narcotics addiction and single male 'sojourners' - men who intended to return to China and had few ties in this country - appeared to be the most susceptible to addiction. Bell and Lau (1966) found that there were, apparently, many elderly bachelors who never got into trouble with the law but who, eventually, wound up in public health hospitals, seeking help for their drug problems. Due

${ }^{13}$ Chen, Pei-Ngor. "The Chinese community in Los Angeles". Social Casework, 51, 1970, 591-598 
to the lack of any current data on such an area, it is not clear whether the rate of narcotic addiction has changed since then. The present author speculates a decline in addiction rate is unlikely because of their continued poor living environment and the unhappy mental state, 
CHAPTER V

TREATMENT CONCERNS AND RECOMNENDATIONS

It may be concluded from reviewing the available literature on this particular topic that mental illness is neither rare among the Chinese population in America nor is there an extremely high rate. However, it is felt that the mental health needs of Chinese are sufficient to warrant greater concern, especially since few individuals have addressed themselves to these needs. In order to have more effective mental health care for the Chinese, the present facilities have to modify their ways of delivering the services.

\section{Modifications in Service Delivery}

Bilingual Therapist. The first big obstacle that has to be overcome is the language barrier existing between the therapist and the clients. Since most of the Chinese immigrants have extremely limited English language capacity, a bilingual therapist is an absolute necessity for successful therapy. Only through the communication using the same language can proper empathy and rapport be built up between therapist and client. Unfortunately, there is a widely recognized shortage of professionally trained personnel to meet the existing demand for bilingual therapists. A good resource for obtaining these potential bilingual chinese therapists would be the large number of Chinese students from 
Hong Kong and Taiwan coming to the United States to receive their university education. If proper incentives are built into their undergraduate training as suggested by Leung (1976), the present author is sure more Chinese students will be attracted into the mental health profession to help their fellow countrymen.

Bi-lingual Paraprofessionals. Another way of responding to the manpower shortage and of recognizing the desirability of having staff who are familiar with the experience of their service population is to advocate the development of new mental health paraprofessionals. These bi-lingual paraprofessionals would be trained to perform both the direct treatment service and preventive activities. Their development would be particularly suited to the Chinese-American population in which language and cultural sensitivity are so critical.

Changes in Therapeutic Concept and Techniques. As mentioned in Chapter one, the process of psychotherapy is essentially a white-middle-class activity, requiring a certain amount of insightful and verbal interpretation of feelings. So far, such insight-oriented interpretations have not been getting any real response from Chinese clients. But if treatments can focus on the present complaints and generate more practical and immediate measures to deal with the perceived causes of difficulties, these treatments may be seen by patients as more helpful. This is especially true in the 
case of Chinese immigrants where a primary cause of emotional problems is little hope for a better future. Their problems are mostly in terms of financial security, complicated by experiences of cultural isolation and alienation of which they are neither aware nor willing to accept. Any attempt to help these patients to gain insight would need be limited to assisting them to see the immediate situation more realistically. The focus of the therapy session is upon assisting the patient to improve his or her current situation. For example, the therapist could point out to the patient the limited but increasing opportunities for change available through new community resources in Chinatown, namely Englishas-a-second-language classes or employment and occupational training programs.

Irregular Drop-In and Brief Treatment. The Chinese are not in the habit of making appointments. As a result, Chinese out-patients are the least inclined to accept the structure of a '50-minute' hour, or a once-weekly, scheduled appointment. Most of them prefer to' just 'drop-in' and feel their way first. If they are forced to come on a regular scheduled basis, the very thought of having to make an appointment before they can ask for service is enough to stop them from coming. Even for the few of them who are willing, they will probably show up very late for the scheduled appointment. One of the weaknesses of the chinese culture is, unfortunately, a lack of punctuality. 
Chinese out-patients often continue in active treatment only until a reasonable homeostasis has been restored. Treatments usually last no longer than six or eight interviews, after which patients will only return for renewal of their medications or will simply drop out altogether. In this case, the therapist could make some sort of contract with the patient at the beginning, emphasizing that any assistance would be given on condition that they promise to participate in the therapy until both parties consider the patient fit to terminate treatment. Such a contract would act as an incentive in motivating patients to engage in therapy for a reasonable period of time without sudden termination. The time span would need to be kept short.

Individual Treatment versus Group Treatment. Chinese seeking treatment are best treated in a one-to-one relationship rather than a group, the reason being that the closeknit quality of the Chinese social system makes them a highly unlikely candidate for any group modalities of treatment. They are eager to keep all of their difficulties within their immediate family. Therefore, any discussion of emotional or interpersonal problems will be made almost impossible in a group situation. Besides, their focus on restoration of homeostasis and their disregard for regular appointments add problems to the use of group treatments.

However, group treatment conforming to the nuclear family and the extended family structure can produce positive 
results. A family treatment team consisting of a pair of opposite sex therapists can be effective in working with

Chinese families, as the following experience indicates:

L, a Chinese-American and a junior high school student, experienced a great many learning difficulties. He habitually skipped school, and, as a result, was unaware of homework assignments. Both of his parents were passive individuals, and were confused by and ashamed of their son's behavior. Also, they were having severe marital problems and were striving to present a facade, pretending their marriage was on solid ground and that it had nothing to do with their son's failing in school.

I, was aware of his parent's problems and defensiveness. He took advantage of their vulnerability by indulging himself whenever he pleased. A family treatment team consisting of a male and one female therapist was quite successful in helping the parents to gain some insight into their problems and to communicate more openly and fully. Attempts to resolve their son's school problems, however, were met with continuous resistance, especially from $I$ himself, who accused the therapists of conspiring with his parents against him. With the permission of the family, a child worker actually the same age as $I$, and a personal friend of the male therapist, was introduced as an additional member of the treatment team. When I repeatedly blamed his parents' marital problems for his own problems, the child worker pointed out that his skipping school was a sign of "coping out" and that the continuation of this activity would only bring him failure. We all have problems, but we have ourselves to blame if we do not live up to our share of responsibilities, ${ }^{\prime}$ added the child worker. The child worker's intervention gradually lessened the guilt feelings of the parents, who later were able to better assume the limiting role in dealing with their son. 14

$14_{\text {ilan, Keun }}$ Ho. "Social work with Asian Americans." Social Casework, Mar. 76, V. 57, \#3, 195-201 
A therapist's application of reciprocal models or any other humanistic techniques in working with Chinese-Americans in groups should capitalize on the authority invested in him as a professional or as an agency representative. Instead of letting the group be self-directive, the therapist needs to be more assertive and structured, particularly in the beginning stages of group interaction. Therapist's inability to provide preliminary structure to the group would only enhance group member anxiety and ambiguity, unwelcome to Chinese patients.

Medication. An example of the Chinese patients' expectation of concrete and service is their preference for medication. The prescribing of medications is a familiar and acceptable form of treatment to them and often leads to relatively prompt symtomatic relief. But one must bear in mind that chinese patients are unable to take medications in the same dosages that are prescribed for other patients. Dosages have to be reduced by on-half, or the patients will complain of feeling drugged. This special phenomenon is the result of differing physical tolerances to the chemicals and/ or culturally determined psychological reactions to taking medications.

\section{A Community Mental Health Program for Chinatown}

One model of programming which seems particularly suited to the needs of Chinese-Americans, as Sue and Sue (1971) have previously suggested, is the community mental health model 
coordinated by local community mental health center.

The rationale of building such a community program is very simple. Since the mental health facilities have not been responsive to the Chinese-American clients because of their traditional western approaches, it will be natural to design a facility specifically for the Chinese-Americans in places where they represent a relatively large segment of the community, namely, Chinatown.

In these community mental health centers, it would be necessary to accomodate both in-patient and out-patient services, so treatments could take place within the local community rather than in far-removed state institution. When in-patients treatment is the only solution, the center would minimize the length of hospitalization as much as possible. This kind of local treatment of mental disorders is of special importance to the Chinese-Americans. When the patient is hospitalized close to the family residence, the family can maintain contact with the patient throughout the hospitalization stage. When the patient is discharged, he may agree more readily to continue with after-care services if he and his family are already familiar with the treatment facilities and staff.

With its convenient location, the center could be in contact with all other vital service agencies such as schools, health services, business, immigration services, housing facilities and entertainment activities very easily. Each of 
these agencies has access to the Chinese-Americans in need of a particular service. By promoting coordination among these agencies with the mental health center, interagency referrals for multi-program clients can be facilitated. Furthermore. cooperative programs can be developed whereby two or more agencies can share their individual resources to accomplish their primary objectives. For example, better care for the elderly can be made available by having social agencies in Chinatown hire the elderly persons to provide services for other old persons, volunteers, possibly. from the churches, could offer help to the non-English speaking oldster.

One serious problem of most Chinese immigrants is their sluggishness in adjusting to new and unfamiliar customs. They have avoided available educational, health, mental health, and welfare services in favor of traditional customs and folkways. Interagency community organization and consultation are effective methods of intervening and altering these attitudes and patterns of behavior.

For actual proof of the community mental health center model's usefulness, one can turn to the recently set up Asian American Counselling and Referal Service in Seattle. This agency has in one year seen nearly the same number of Asian patients as did the seventeen community mental health facilities over a period of three years (sue and Mckinney, $1974)$. 
Further Research

Research and surveys should be conducted into the changing Chinese-American family structure, cultural patterns, stages of assimilation, and social behavior in order to reach a greater understanding of their emotional problems in relation to the changing needs of the Chinese people.

Most community programs for Chinese-Americans have emphasized service but have neglected the systematic study of the outcome: Obviously, the success or failure of any program must be determined. Too much money is wasted, often, on programs which do not achieve intended goals. Research is helpful only to the extent it meets the needs of individuals.

Only fairly recently, one such research program has been set up. It is the Asian-American Mental Health Research Center (AAMHRC), located at La Jolla, near San Diego, California. The center is funded by an initial grant from National Institution of Mental Health (NINH), and is structured to meet six major objectives: to initiate and facilitate preliminary studies; to develop training facilities for researchers and scholars; to co-ordinate research efforts; to provide technical assistance to Asian American communities; to establish a data resource bank on Asians in America; and to seek continued funding for research and development. With the AAMHRC program as the start-off point, the present author is confident that other similar programs will 
be set up to improve the mental health care for not only the Chinese-Americans, but for all Asian-Americans who, for the past century have been almost completely neglected in this important area of concern. 
A SELECTED BIBLIOGRAPHY Note: The Tannal is pubieshed

Abbot, Kenneth A. and Elizabeth $I$. Juvenile Delinquency in San Francisco's China-American community: 1961-1966. Journal of Sociology, 1968,4,45-46

Abel, T.M. and Hsu, Francis L.K. Some aspects of personality of Chinese as revealed by the Rorschach Test. Rorschach Research Exchange and Journal of Projective Technique, 1949, 13, 285-301

Ball, John C. and Lau, M.P. The Chinese Narcotic Addicts in the United States. Social Farces, 1966, 45, \#1, $68-72$

Barnett, M.J. Alcoholism in the Cantonese of New York City in Etiology of Chronic Alcoholism, Oscar, Diethelm (eds.). Madison, University of Wisconsin Press. 1955. $179-227$

Berk, Bernard B. and Hirata, Cheng, I. Mental Illness Among the Chinese: Myth or Reality? Journal of Social Issues, $1973,29, \# 2,149-166$

Berne, E. Some Oriental Mental Hospital. American Journal of Psychiatry, 1950, 106, 376-383

Bowman, K. Psychiatry in China. American Journal of Psychiatry, 1948, 105, 70-71

Brown, 'T.R., Stein, K.M., Huang, K. and Harvis, D.E. Mental Illness and the Role of Mental Health Facilities in Chinatown. Asian American Psychological Perspectives, S. Sue and N. Wagner (eds.). 1973, Palo Alto, Seience and Behavior Books

Carlson, Eric J. Counseling in Nature Context, Canada's Mental Health, 1975, 23, \#1, 7-9

Cerny, J. Chinese Psychiatry. International Journal of Psychiatry, 1965, 1, 229-247

Chance, H.A., Rin, H. and Chu, H. Modernization, value identification and mental health: a cross-cultural study, Anthropologica, 1967, 8, \#2, 197-216

Chen, P.N. The Chinese Community in Ios Angeles. Social Casework, 1970, 51, 591-598 
JChou, S.K. and Mi, C. Relative neurotic tendency in Chinese and American students. Journal of Social Psychology, $1937,8,155-184$

Collier, Herbert $\mathrm{L}$. The Patient with somatic symptoms. Problems in Psychotherapy: an exlectic approach, W. Klopfer and M. Reed (eds.), Washington, D.C., Hemisphers Publishing Corporation, 1974, 73-96

Cooper, J.M. Mental disease situation in certain culture a new field for research. Journal of Abnormal and Social Psychology, 1934, 29, 10-17

Fong, Stanley L.M. Assimilation and Changing social roles of Chinese-Americans, Journal of Social Issues, 1973. 29. \#2, 115-12?

Goldberg, I.R. Diagnosticians VS. diagnostic signs: The diagnosis of Psychosis vs. neurosis from the MMPI, 1965, Psychological Monographs. 79

Homma-True, Reiko. Characteristics of contrasting Chinatowns, 2, Oakland, California. Social Casework, 1976, 57, \#3, $155-159$

Hsu, Francis I.K. Americans and Chinese: two ways of Iife, 1953. New York; H. Schuman

Hsu, Francis L.K. (ed.) Aspects of culture and personality, 1954, New York, Abeland-Schuman

Hsu, Francis I.K. (ed.) Psychological Anthropology: approaches to culture and personality, 1961, Illinois, The Dorsey Press, Inc.

Jew, C.C. and Brody, S.A. Mental illness among the Chinese, I, Hospitalization Notes over the past century, Comprehensive Psychiatry, 1967, 8, 129-134

Jung, rarshall. Characteristics of Contrasting Chinatowns, I, Philadelphia, Pennsylvania, Social Casework, 1976, 57. \#3, 149-154

Kalish, Richard A., Yuen, Samuel Y. Americans of East Asian Ancestry: Aging and the Aged. The Gerontologist, 1971, $2,36-47$

Kimmich, R.A. Ethnic aspects of Schizophrenia in Hawaii, Psychiatry, $1960,23,97-102$ 
Kitano, Harry $\mathrm{H}$. Mental illness in four cultures. Journal of Social Psychology, 1970, 80, 121-134

Kitano, Harry H., Sue, Stanley. The INodel Minorities. Journal of Social Issues, 1973, 29, \#2, 1-9

Koran, I.M. Psychiatry in Mainland: History and recent status. American Journal of Psychiatry, 1972, 128, \#8, 970-978

Kung, S.W. Chinese in American Iife: some aspects of their. history,status, problems and contributions, 1962, Seattle, University of Washington Press, 53

Kushida, Arlene Hori and others. A training program for Asian and Pacific Islander Americans. Social Casework, 1976

Lee, Rose H. Delinquent neglected and dependent Chinese boys and girls of the San Francisco Bay region. Journal of Social Psychology, 1952, 36, \#1, 15-34

Leung, Alex $\mathrm{C}$. In America, do as what the Americans do. Some personal adjustments I undertook as being a foreign student in the lnited States, 1974, unpublished paper

Leung, Alex C. Clinical psychology training program for minority groups, 1976, unpublished paper

Iin, Tsung-Yi. A study of the incidence of mental disorders in Chinese and other cultures, 1953, Psychiatry, 16, $313-336$

Iin, William T. and Yamada, Wariko. The Asian American mental health research center. Social Casework, 1976, 57, \#3, $136-138$

Man, Keung-Ho. Social work with Asian Americans. Social Casework, 1976, 57, \#3, 195-201

Viarsella, A.J., Kinzie, D. and Gordon P. Depressive patterns among American college students of Caucasian, Chinese and Japanese ancestry, 1971, paper presented at the Conference on Culture and Mental Health in Asian and the Pacific, Honolulu

Pai, 'T., Sung, S.M. and Hsu, E.H. The application of Thurston's Personality Schedule to Chinese subjects, 1937, Journal of Social Psychology, 8, 47-72 
Pedersen, S. Psychopathological reactions to extreme social displacements (refugee neurosis). 1949. Psychoanalytic Review, 36, 344-54

Plog, Stanley C. and Edgerton, Robert C. (ed.), Changing Perspectives in Mental IIlness, 1969. New York, Reinhart and Winston

Richards, T.W. The Chinese in Hawaii: a research report, in Aspects of Culture and Personality. Francis Hsu (ed.), 1954, New York, Abeland-Schuman, 67-89

Rin, H. A study of the aetiology of Koro in respect to the Chinese concept of illness, 1965. International Journal of Social Psychiatry, 11, 7-13

San Francisco Chinese Community Citizen's Survey and FactFinding Committee Report, 1969, San Francisco, H.J. Carle and sons

Scofield, R.W. and Sun, C.W. A comparative study of the differential effect upon personality of Chinese and American child training practices, 1970, Journal of Social Psychology, 52, 221-224

Shen, Eugene, Differences between Chinese and American reactions to the Bernreuter Personality Inventory, Journal of Social Psychology, 1936, 7, 471-474

Shih, L.Y., Lee, H.S. and Ho, Y.H. A study of the aetiology of Koro in respect to the Chinese concept of illness. 1965. International Journal of Social Psychiatry. 11. $7-13$

Shimazaki, R. and Takahaski, R. Psychiatric problems of students sent abroad to study - a study on mental disturbances, especially schizophrenia and depression during studying abroad, 1967. Clinical Psychiatry, 9, $564-571$

Sommers, V.S. An experiment in group psychotherapy with members of mixed minority groups, 1953. International Journal of Group Psychotherapy, 3, 265

Sommers, V.S. Identity conflict and acculturation problems in Oriental Americans, 1960, American Journal of Orthopsychiatry, $30 ; 637-644$

Sue, Derald W. and Kirk, B.A. Asian-American use of counseling and psychiatric service on a college campus, 1975. Journal of Counseling Psychology, 22, \#1, 84-86 
WSue, Derald W. and Kirk, B.A. Differential characteristics of Japanese-Americans and Chinese-American college students, 1973, Journal of Counseling Psychology, 20, \#2

$\checkmark$ Sue, Derald W. and Kirk, B.A. Psychological characteristics of Chinese-American students, Journal of Counseling.. $1972,6,471-478$

Sue, Derald $w$. and Sue, Stanley. Counseling Chinese-Americans, 1972, Personnel and Guidance Journal, 50, 637-44

Sue, Derald $W$, and Sue, Stanley, Ethnic minorities: resistances to be researched, 1972, Professional Psychology, 3. $11-17$

Sue, Stanley, Sue, Derald $W$. and Sue, David. Asian Americans as a minority group, 1975. American. Psychologist, 30 , 906-910

Sue, Stanley and Nininney, H. Asian Americans in the community health care system, 1975. American Journal of Orthopsychiatry, $45,111-118$

Sue, Stanley and Wagner, Nathaniel N. Asian Americans: Psychological Perspectives, 1973, Palo Alto, Science and Behavior Books

$\checkmark$ Sue, Stanley and Sue, Derald W. MMPI Comparisons between Asian Americans and non-Asian students utilizing a student health psychiatric clinic, 1974, Journal of Counseling Psychology, 21, \#5, 423-427

Sue, Stanley and Kitano, Harry H. Stereotypes as a measure of success, 1973, Journal of Social Issues, 29, \#2, $83-98$

$\checkmark$ Sue, Stanley, Training of third-world students to function as counselors, 1973. Journal of Counseling Psychology, 20, \#1, 63-78

Tseng, W.S. and Hsu, J, Chinese culture personality formation and mental illness, 1969. International Journal of Social Psychiatry, 16, \#1, 5-14

Tseng, W.S. The concept of Personality in Confucian thought, 1973. Psychiatry, 36, \#2, 191-202

Tseng, W.S. The development of psychiatry concepts in traditional Chinese medicine, 1973. Archives of General

Psychiatry, 29, 569-575 
Tseng, W.S. A paranoid family in Taiwan: a dynamic study of folie-a-famille, 1969, Archives of General Psychiatry, $21, \# 1,55-63$

Tseng, W.S. Psychopathologic study of obsessive-compulsive neurosis in Taiwan. 1973. Comparative Psychiatry. 14,

Tsuang, M.T. Birth order and maternal age of psychiatric in-patients, 1966, British Journal of Psychiatry, 112, \#492, 1131-1141

Tsuan, M.T. Psychiatry genetics in Taiwan, 1972, International Journal of Mental Health, 1, 221-230

Tyhurst, I. Displacement and migration: a study in social Psychiatry, 1951, American Journal of Psychiatry, 107. $567-568$

Veith, Ilza. The Far East, Reflections on the Psychological Foundations in J. Howells (ed.) World History of Psychiatry, 1975. New York, Brunner Mazel, 662-703

Vontress, C.E. Racial differences: impediments to rapport, 1971, Journal of Counseling, 18, 7-13

Watanabe, Colin, Self-expression and the Asian-Americans experience, 1973, Personnel and Guidance Journal, 51, $390-396$

Wong, Linda. The Esther Iau Trial: a case study of oppression and sexism, 1975. Amerasia, 3, \#1, 16-26

Woods, A.H. The nervous disease of the Chinese, 1929, Archive of Neurology and Psychiatry, 21, 542-570

Wright, B.R. Social aspects of change in the Chinese family pattern in Hong. Kong, 1964, Journal of Social Psychiatry, 63, 31-39

Yamamoto, J., James, O.C. and Palley, N. Cultural problems in psychiatric therapy, 1968, Archives of General Psychiatry, $19,45-49$

Yap, P.M. Koro - a culture bound depersonalization syndrome, 1965, British Journal of Psychiatry, 111, 470

Yap, P.M. Hypereridism and attempted suicide in Chinese, 1958, Journal of Nervous Mental Disease, 127, 34-41 
63

Yap, P.M. Mental disease peculiar to certain cultures: a program survey of comparative psychology, 1951, Jourhal of Mental Science. 97. 313-327

Yap, P.M. Phenomenology of effective disorders in Chinese and other cultures in Transcultural Psychiatry. A deReuck and $R$. Porter (eds.), 1967, Boston, Little, Brown

XYap, Pow Ming, Suicides in Hong Kong, 1958, Journal of Mentat Science, 104, 266-301

YYeh, Eng-Kung. Paranoid Manifestation among Chinese students studying abroad: some preliminary findings, in Transcultural Research in Mental Health, V. II of Mental Health Research in Asia and the Pacific. William Libra (ed.), 1972, Honolulu, University of Hawaii Press

Zuni, I.M. and Rubin, R.T. Paranoid psychotic reactions in foreign students from non-Western countries, 1967. $\frac{\text { American College Health Association Journal, }}{226} 15,220-$ 